\title{
Cloning and Functional Assessment of the Recombinant Human Hepcidin-25 in the Baculovirus Expression System
}

\author{
Yaghoub Yazdani $^{1,2,3^{*}}$, Neda Keyhanvar ${ }^{3}$ and Alijan Tabaraei ${ }^{1}$ \\ ${ }^{I}$ Infectious Diseases Research Center; Golestan University of Medical Sciences; Gorgan, Golestan - Iran. \\ ${ }^{2}$ Laboratory Sciences Research Center; Golestan University of Medical Sciences; Gorgan, Golestan - Iran. \\ ${ }^{3}$ Department of Medical Biotechnology; Golestan University of Medical Sciences; Gorgan, Golestan - Iran
}

\begin{abstract}
Hepcidin is the primary regulatory hormone responsible for lowering the iron content in the blood circulation. Due to its biodegradability and low cytotoxicity, hepcidin is considered as an alternative for iron chelators. The baculovirus expression system may be suitable for human hepcidin production because the expressed proteins generally exhibit proper folding, post-translational modifications, and oligomerization. Using data from two vector maps, pFastBac1 and pFastBac HTB, a unique vector was designed encoding human hepcidin-25 as fusion recombinant peptide. Expression analysis showed that it was expressed as a peptide with a molecular weight near to $5 \mathrm{kDa}$. After purification and TEV treatment, findings revealed that recombinant human hepcidin-25 was functional and its effect was dose dependent $(P=0.001)$. It was concluded that baculovirus expression was a suitable expression system for production of functional recombinant human hepcidin-25.
\end{abstract}

Key words: Hepcidin-25, Iron metabolism, SF-9 expression system

\section{INTRODUCTION}

Hepcidin is a small cysteine-rich antimicrobial peptide that functions as main iron regulatory hormone (Ganz 2003; 2006). Hepcidin exhibits antimicrobial activity against a variety of pathogens, including bacteria, viruses, and fungi (Krause et al. 2000; Park et al. 2001). It lowers iron content in response to iron accumulation, hypoxia, and inflammation (Ganz and Nemeth 2006; Nemeth and Ganz 2006). Hepcidin inhibits iron uptake from intestinal cells and iron release from reticuloendothelial cells, particularly macrophages (Nicolas et al. 2002). It acts by binding to ferroportin, the only iron exporting channel in mammals (De Domenico et al. 2008) . Hepcidin is primarily expressed in liver in the form of an 84-amino acid precursor, which undergoes various post-translational modifications to form the mature active hepcidin-25(Pigeon et al. 2001). This cysteine-rich peptide contains four disulfide bonds.

There are several methods for the production and purification of hepcidin. However, each of these methods has limitations. Extraction and purification of a natural form of hepcidin from urine or plasma resulted in low yield (Ganz 2003; 2006). A second method is chemical synthesis of hepcidin, which requires various refolding procedures. In addition, synthetized hepcidin molecules have different sizes that may interfere with hepcidin function (Rivera et al. 2005). Another method for hepcidin production is the biological expression system. Incomplete post-

*Author for correspondence: yazdani@goums.ac.ir 
translational modification in the bacterial expression system (Carvalho et al. 2012), differences in glycosylation encountered in the yeast expression system (high mannose) (Durocher and Butler 2009), and the high cost of production when using the mammalian expression system prompted to use the baculovirus expression system (BES) for human hepcidin production. Post-translational modifications such as glycosylation, acylation, amidation, carboxymethylation, and phosphorylation in BES are similar to those found in mammalian cells (Patterson et al. 1995). In addition, proteins purified using BES is devoid of toxic bacterial components, such as lipopolysaccharide (LPS) (Hervas-Stubbs et al. 2007).

This work studied the cloning and expression of human hepcidin-25 using BES. Using recombinant DNA technology and the cloning sites of pFastBac1 and pFastBac HTB vectors, a unique construct encoding human hepcidin-25 was designed. This novel vector encoded hepcidin- 25 as a fusion protein with a His-tag and TEV recognition sites at its $\mathrm{N}$-terminus. Expression of the recombinant human hepcidin-25 was analyzed by SDS-PAGE and Western blot. Finally, functional assessment was performed by the evaluation of the hepcidin effects on serum iron concentration. To our knowledge, this is the first report describing expression of functional human hepcidin-25 in the BES.

\section{MATERIALS AND METHODS}

\section{Designing the coding sequence for recombinant human hepcidin}

According to the codon preference observed in BES and the cloning site map of pFastBac HTB as well as pFastBac1 vectors, a 174 bp coding sequence containing His-tag, TEV recognition sites and hepcidin-25 sequence was synthesized (Shinegene, China). For direct cloning, restriction sites of BamHI and EcoRI enzymes were introduced respectively at the $5^{\prime}$ and $3^{\prime}$ ends of the designed sequence. The synthesized sequence was cloned into pFastBac1 vector (Invitrogen, USA). Then, the cloning was verified by restriction digestion, PCR amplification using specific primers, and DNA sequencing using universal M13 primers.
Production of recombinant shuttle bacmid and recombinant baculovirus

Recombinant bacmid was produced in Max efficiency DH10 Bac competent cells (Invitrogen, USA). M13 primers were used for preliminary assessment of recombinant bacmid. Orientation of the hepcidin coding sequence during homologous recombination was analyzed by PCR using M13 forward and Hepcidin reverse 5' [GAATTCGGTTCTACGTCTTGCAGCACATCC] 3' Primers. Finally, confirmed recombinant bacmid was prepared by MidiPrep kit (Invitrogen).

The insect cell line Sf9 (Pasteur Institute, Iran) was used for recombinant baculovirus production. Details of the experiments are mentioned elsewhere (Yazdani et al. 2011).

\section{Expression analysis of the recombinant human hepcidin-25}

For hepcidin expression, Sf9 cells were transfected with recombinant baculovirus. Preliminary assessment showed that hepcidin expression was optimal when cells were incubated for $72 \mathrm{~h}$ at a multiplicity of infection (MOI) of 10 .

Recombinant hepcidin-25 expression was examined by sodium dodecyl sulfatepolyacrylamide gel electrophoresis (SDS-PAGE) and Western blot analyses. For Western blot analysis, protein samples were loaded on a $15 \%$ Poly acrylamide gel. The loaded proteins were separated by SDS-PAGE and transferred to a nitrocellulose membrane and hepcidin expression was verified using anti hecidin-25 monoclonal antibody (Alpha Diagnostic, USA). A detailed description of the protocol used for Western blot analysis can be found elsewhere (Yazdani et al. 2011; 2013)

\section{Hepcidin effect on iron circulation in animal model}

Three to four week-old male C57BL/6 mice were purchased from the Pasteur Institute of Iran. Mice were maintained on a normal iron diet for two weeks. Then, mice were treated with a single dose of 25 and $50 \mu \mathrm{g}$ of the recombinant human hepcidin-25, intraperitonealy. The treated mice were sacrificed $24 \mathrm{~h}$ post injection for the evaluation of serum iron. Blood was collected using cardiac puncture technique and serum iron was evaluated by iron assay kit. A detailed description of the protocol can be found elsewhere (Yazdani et al. 2013). 


\section{RESULTS AND DISCUSSION}

\section{Cloning the coding sequence of recombinant human hepcidin}

Based on bioinformatic analysis and the restriction maps of pFastBac1 and pFastBac HT B vectors, a novel construct encoding human hepcidin-25 was design.

Using GenScript software, the codon adaptation index (CAI) was estimated for the designed sequence to ensure optimal expression in the BES. The CAI was estimated to be 0.72 , a reliable index for proper expression. Finally, the designed sequence was synthesized. PCR and DNA sequencing analyses were performed to confirm the recombinant $\mathrm{pFastBac1-Hepc25}$ vector. Lane 1 in Figure 1A shows the $174 \mathrm{bp}$ band corresponding to the designed coding sequence. For further confirmation, DNA sequencing using universal M13 Primers was performed. A comparison of DNA sequencing result with the sequence found at NCBI confirmed that the cloning was successful.

PCR analysis using M13 primers was used for the confirmation of recombinant bacmid. The agarose gel electrophoresis pattern showed a band close to $2,474 \mathrm{bp}$ in length $(2,300 \mathrm{bp}$; bacmid transposed with pFastBac1 + $174 \mathrm{bp}$; hepcidin sequence), indicating the correct homologous recombination between pFastBac1-Hepc 25 and bacterial bacmid (Fig. 1B, Lanes 1-4). The orientation of the recombinant bacmid was confirmed using M13 forward and hepcidin reverse primers. The bands close to $1700 \mathrm{bp}$ in Lanes 1-3 of Figure 1C illustrate the correct orientation of the recombinant bacmid. Subsequently, the bacmid was used for recombinant baculovirus production in Sf9 cells.

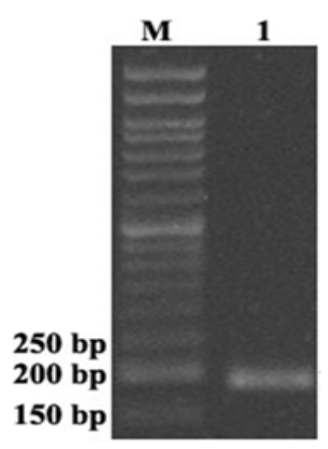

A

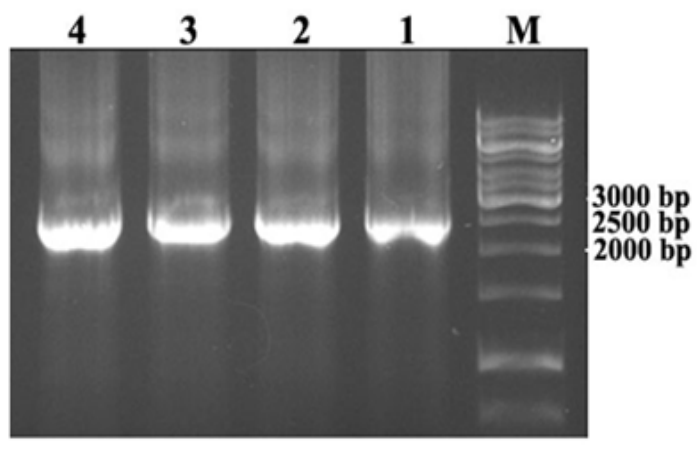

B

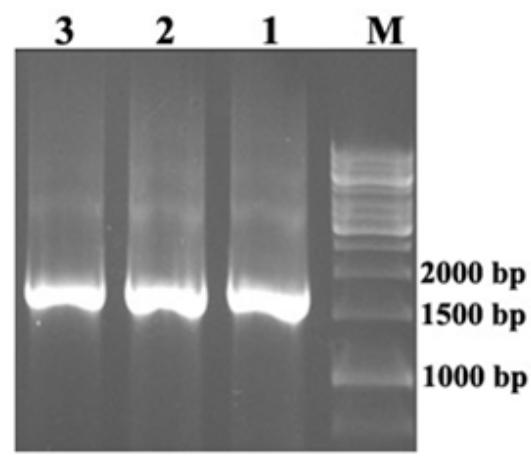

C

Figure 1 - (A) Agarose (1.5\%) gel electrophoresis pattern of the PCR product obtained from recombinant $\mathrm{pFastBac1-Hepc25}$ vector (hepcidin specific primers were used for PCR amplification). The $174 \mathrm{bp}$ band in Lane 1 illustrates the presence of human hepcidin-25 in the prepared construct. (B) Agarose (0.8\%) gel electrophoresis pattern of the PCR product from recombinant bacmid (M13 universal primers were used for PCR amplification). The 2474 bp band in Lanes 1-4 illustrates successful homologous recombination. (C) Agarose $(0.8 \%)$ gel electrophoresis pattern of the PCR product from recombinant bacmid (M13 forward and hepcidin reverse primers were used for PCR amplification). The 1,700 bp band in Lanes 1-3 illustrates the presence of human hepcidin-25 in recombinant bacmid.

\section{Expression analysis of the recombinant hepcidin}

Sf9 cells were used for transient recombinant hepcidin-25 production. Hepcidin expression was assessed $72 \mathrm{~h}$ after baculovirus infection. The results of the SDS-PAGE analysis are shown in Figure 2. The band close to $5 \mathrm{kDa}$ illustrated the recombinant human hepcidin-25 expression (Fig. 2 Lane 1). Finally, Western blot analysis was performed using monoclonal anti-hepcidin-25 antibody. As shown in Figure 3, Lane 2, the band measuring approximately $5 \mathrm{kDa}$ indicated the recombinant human hepcidin- 25 expression. 


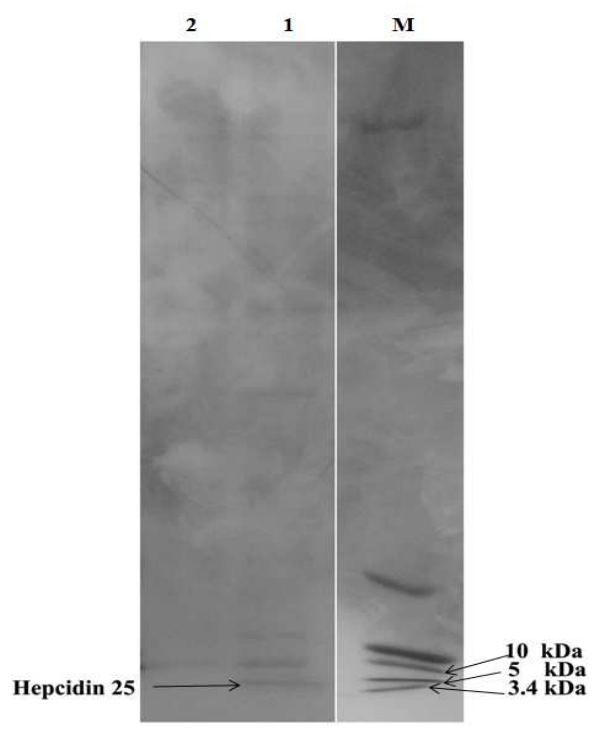

Figure 2 - Human hepcidin-25 expression in Sf9 cells. M: molecular marker (3.4 to $100 \mathrm{kDa}$ ), Lane 1: lysate of Sf9 cells transfected with recombinant bacmid. Lane 2: lysate of Sf9 cells not transfected with recombinant bacmid. The peptide band with a molecular weight near to $5 \mathrm{kDa}$ indicated expression of fusion hepcidin-25.

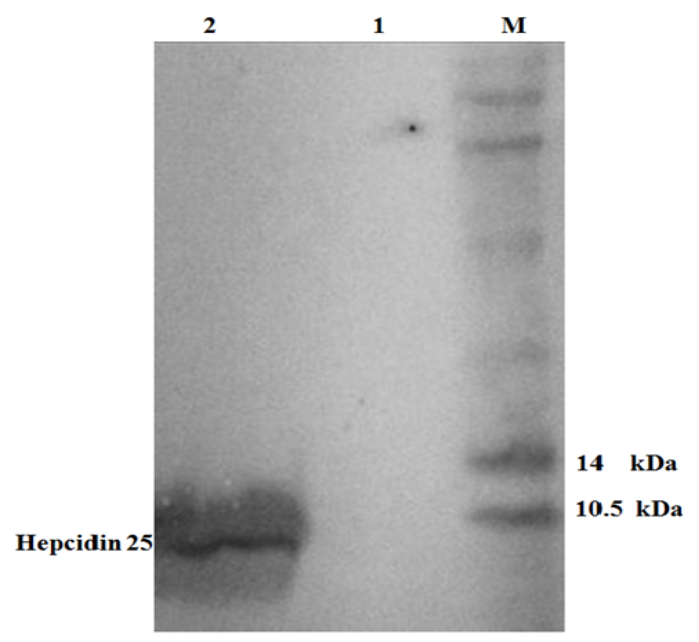

Figure 3 - Immunoblott analysis of human hepcidin-25 in SF-9 cell. M: pre-stained molecular marker (10.5 to $175 \mathrm{kDa})$; lane1: SF-9 cells transfected with not recombinant baculovirus; lane2: SF-9 cell transfected with recombinant bacmid.

\section{Functional study of the recombinant human hepcidin-25}

The recombinant human hepcidin-25 was purified using DEAE column and the His-tag was cleaved by tobacco etch virus (TEV) protease (Yazdani et al. 2011). Functional assessment was performed by the evaluation of the hepcidin effects on serum iron concentration (Fig. 4). The obtained data indicated that recombinant human hepcidin-25 had significantly decreased the iron concentration in blood circulation $(P=.000)$. Reduction in the serum iron was dose dependent so that $50 \mu \mathrm{g}$ of human hepcidin-25 had higher effect on iron concentration $(P=0.001)$.

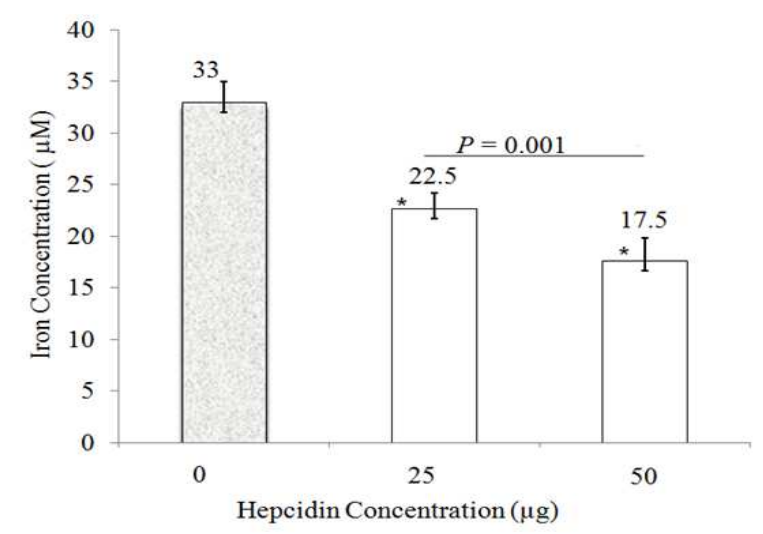

Figure 4-Hepcidin effects on serum iron concentration. The mice received a single dose of 25 and 50 $\mu \mathrm{g}$ recombinant human hepcidin-25 separately. Data expressed as the means $+/$ SEM of six mice and $P$ values tested by $t$ test. The significant level for $P$ value was $P \leq$ 0.05 (*means $P \leq 0.05)$. There was significant difference between 25 and $50 \mu \mathrm{g}$ of the recombinant mouse hipcidin-1 $(P=0.001)$.

Antimicrobial peptides are extensively studied in the field of innate immunity due to their multifunctional roles in physiology (Zasloff 2002). Hepcidin, an antimicrobial peptide, plays an important role in iron metabolism (Ganz 2003; 2006). Hepcidin isolated from various species exhibit antimicrobial properties against a variety of microorganisms (Anderson et al. 2002; Lauth et al. 2005). Krause et al. (2000) reported the first purification of hepcidin from human plasma and called it LEAP-1. Park et al. (2001) named it hepcidin due to its antimicrobial properties and hepatic origin.

A previous study has shown that mouse hepcidin-1 produced in BES is able to lower the serum iron levels (Yazdani et al. 2011). Several reports have described the cloning and expression of hepcidins in various species (Gerardi et al. 2005; Zhang et al. 2005; Gagliardo et al. 2008; Greenshields et al. 2008; Koliaraki, et al. 2008; Lee et al. 2008; Srinivasulu et al. 2008; Cai et al. 2012). The bacterial expression system is cost- effective, and 
generally the yields are high. However, in comparison with the mammalian expression system, recombinant proteins purified from bacteria generally show incomplete posttranslational modifications (Yazdani et al. 2011). Although the yeast expression system presents a better alternative for eukaryotic protein production, this system often gave rise to high mannose glycosylation, a modification that may lead to lower half life and efficacy of hepcidin (Durocher and Butler 2009). The BES has efficient machinery for post-translational modification of proteins (mostly like mammalian) (Kost et al. 2005; Yazdani et al. 2011). Ninety-five percent of the recombinant proteins expressed in the BES are biologically active (Patterson et al. 1995). Another important advantage of this expression system is that the entire process of expression and purification can be done in an environment devoid of cytotoxic bacterial components such as LPS (Hervas-Stubbs et al. 2007; Yazdani et al. 2011).

The BES has been used for the production of several antimicrobial peptide (Yazdani et al. 2011). Studies have shown that the expressed proteins contained correct disulfide bonds and post-translational modifications including glycosylation, phosphorylation and proteolitic processing (Greenshields et al. 2008).

The designed construct for the coding of human hepcidin-25 contained His-tag, TEV recognition site and coding sequence of human hepcidin immediately following ATG codon. The Nterminal His-tag was introduced to enable nickelbased purification. Recognition site for TEV was introduced so as to enable the removal of His-tag from the purified hepcidin-25. This strategy also allowed for recombinant hepcidin production with a minimum number of extra amino acids at its $\mathrm{N}$ terminus. Hepcidin coding sequence has only one neutral extra amino acid (glycine). Because of its neutral nature, the added glycine is not considered to significantly affect the peptide folding and efficiency (Ladurner and Fersht 1997).

Based on the present results, an MOI of 10 and $72 \mathrm{~h}$ post infection was identified as suitable condition for recombinant hepcidin-25 expression (Yazdani et al. 2011).

Analysis of the designed sequence with ExPASy software showed that the future expressed hepcidin-25 peptide should have an expected molecular weight of approximately $5.8 \mathrm{kDa}$ based on its amino acid sequence. The results of SDSPAGE analysis showed a band of approximately 5
$\mathrm{kDa}$ that was consistent with expected recombinant hepcidin-25 (Fig. 2).

Previous study has demonstrated that recombinant mouse hepcidin-1 significantly decreased ferroportin in J774A cell line. But, after infusion to the mice peritoneal cavity, the recombinant mouse hepcidin-1 mainly displayed a local activity on peritoneal macrophages (Yazdani et al. 2013).

For functional assessment, the mice were given a single dose of 25 and $50 \mu \mathrm{g}$ of the recombinant human hepcidin-25, separately. The serum iron was assessed $24 \mathrm{~h}$ post-injection. Present findings showed a reduction in serum iron in both treated mice $(P=0.000)$. The results revealed that hepcidin effect was dose dependent so that mice treated with $50 \mu \mathrm{g}$ of recombinant human hepcidin-25 caused a more reduction in serum iron concentration (Fig. 4).

\section{CONCLUSIONS}

This study was the first work that considered cloning and functional assessment of hepcidin-25 using a novel coding sequence in the BES. Results suggested that the BES was a suitable expression system for the production of small functional peptide such as human hepcidin-25.

\section{ACKNOWLEDGMENTS}

This study was funded by the Golestan University of Medical Sciences. Award No: 2309.

\section{REFERENCES}

Anderson GJ, Frazer DM, Wilkins SJ, Becker EM, Millard KN, Murphy TL, et al. Relationship between intestinal iron-transporter expression, hepatic hepcidin levels and the control of iron absorption. Biochem Soc Trans. 2002; 30(4): 724-726.

Cai L, Cai JJ, Liu HP, Fan DQ, Peng H, Wang KJ. Recombinant medaka (Oryzias melastigmus) prohepcidin: Multifunctional characterization. Comp Biochem Physiol B Biochem Mol Biol. 2012; 161(2):140-147.

Carvalho RJ, Cabrera-Crespo J, Tanizaki MM, Goncalves VM. Development of production and purification processes of recombinant fragment of pneumococcal surface protein A in Escherichia coli using different carbon sources and chromatography sequences. Appl Microbiol Biotechnol. 2012; 94(3): 683-694. 
De Domenico I, Nemeth E, Nelson JM, Phillips JD, Ajioka RS, Kay MS, et al. The hepcidin-binding site on ferroportin is evolutionarily conserved. Cell Metab. 2008; 8(2): 146-156.

Durocher Y, Butler M. Expression systems for therapeutic glycoprotein production. Curr Opin Biotechnol. 2009;20(6):700-707.

Gagliardo B, Faye A, Jaouen M, Deschemin JC, Canonne-Hergaux F, Vaulont S, et al. Production of biologically active forms of recombinant hepcidin, the iron-regulatory hormone. FEBS J. 2008; 275(15): 3793-3803.

Ganz T, Nemeth E. Iron imports. IV. Hepcidin and regulation of body iron metabolism. Am J Physiol Gastrointest Liver Physiol. 2006; 290(2): 199-203.

Ganz T. Hepcidin, a key regulator of iron metabolism and mediator of anemia of inflammation. Blood. 2003; 102(3): 783-788.

Ganz T. Hepcidin-a peptide hormone at the interface of innate immunity and iron metabolism. Curr Top Microbiol Immunol. 2006; 306: 183-198.

Gerardi G, Biasiotto G, Santambrogio P, Zanella I, Ingrassia R, Corrado M, et al. Recombinant human hepcidin expressed in Escherichia coli isolates as an iron containing protein. Blood Cells Mol Dis. 2005; 35(2): 177-181.

Greenshields AL, Knickle LC, Syvitski R, Douglas SE. Strategies for recombinant expression of small, highly disulphide-bonded, cationic antimicrobial peptides. Protein Pept Lett. 2008; 15(9): 985-994.

Hervas-Stubbs S, Rueda P, Lopez L, Leclerc C. Insect baculoviruses strongly potentiate adaptive immune responses by inducing type I IFN. J Immunol. 2007; 178(4): 2361-2369.

Koliaraki V, Marinou M, Samiotaki M, Panayotou G, Pantopoulos K, Mamalaki A. Iron regulatory and bactericidal properties of human recombinant hepcidin expressed in Pichia pastoris. Biochimie. 2008; 90(5): 726-735.

Kost TA, Condreay JP, Jarvis DL. Baculovirus as versatile vectors for protein expression in insect and mammalian cells. Nat Biotechnol. 2005; 23(5): 567575.

Krause A, Neitz S, Magert HJ, Schulz A, Forssmann WG, Schulz-Knappe P, et al. LEAP-1, a novel highly disulfide-bonded human peptide, exhibits antimicrobial activity. FEBS Lett. 2000; 480(2-3): 147-150.

Ladurner AG, Fersht AR. Glutamine, alanine or glycine repeats inserted into the loop of a protein have minimal effects on stability and folding rates. $\mathrm{J} \mathrm{Mol}$ Biol. 1997; 273(1): 330-337.

Lauth X, Babon JJ, Stannard JA, Singh S, Nizet V, Carlberg JM, et al. Bass hepcidin synthesis, solution structure, antimicrobial activities and synergism, and in vivo hepatic response to bacterial infections. $J$ Biol Chem. 2005; 280(10): 9272-9282.
Lee SJ, Park IS, Han YH, Kim YO, Reeves PR. Soluble expression of recombinant olive flounder hepcidin I using a novel secretion enhancer. Mol Cells. 2008; 26(2): 140-145.

Nemeth E, Ganz T. Regulation of iron metabolism by hepcidin. Annu Rev Nutr. 2006; 26: 323-342.

Nicolas G, Bennoun M, Porteu A, Mativet S, Beaumont C, Grandchamp B, et al. Severe iron deficiency anemia in transgenic mice expressing liver hepcidin. Proc Natl Acad Sci. 2002; 99(7): 4596-4601.

Park CH, Valore EV, Waring AJ, Ganz T. Hepcidin, a urinary antimicrobial peptide synthesized in the liver. J Biol Chem. 2001; 276(11): 7806-7810.

Patterson RM, Selkirk JK, Merrick BA. Baculovirus and insect cell gene expression: review of baculovirus biotechnology. Environ Health Perspect. 1995; 103 (7-8):756-759.

Pigeon C, Ilyin G, Courselaud B, Leroyer P, Turlin B, Brissot $\mathrm{P}$, et al. A new mouse liver-specific gene, encoding a protein homologous to human antimicrobial peptide hepcidin, is overexpressed during iron overload. J Biol Chem. 2001; 276(11): 7811-7819.

Rivera S, Nemeth E, Gabayan V, Lopez MA, Farshidi D, Ganz T. Synthetic hepcidin causes rapid dosedependent hypoferremia and is concentrated in ferroportin-containing organs. Blood. 2005; 106(6): 2196-2199.

Srinivasulu B, Syvitski R, Seo JK, Mattatall NR, Knickle LC, Douglas SE. Expression, purification and structural characterization of recombinant hepcidin, an antimicrobial peptide identified in Japanese flounder, Paralichthys olivaceus. Protein Expres Purif. 2008; 61(1): 36-44.

Yazdani Y, Keyhanvar N, Kalhor HR, Rezaei A. Functional analyses of recombinant mouse hepcidin-1 in cell culture and animal model. Biotechnol Lett. 2013; 35(8): 1191-1197.

Yazdani Y, Sadeghi H, Alimohammadian M, Andalib A, Moazen F, Rezaei A. Expression of an Innate Immune Element (Mouse Hepcidin-1) in Baculovirus Expression System and the Comparison of Its Function with Synthetic Human Hepcidin-25. Iran J Pharm Res. 2011; 10(3): 559-568.

Zasloff M. Antimicrobial peptides of multicellular organisms. Nature. 2002; 415(6870): 389-395.

Zhang H, Yuan Q, Zhu Y, Ma R. Expression and preparation of recombinant hepcidin in Escherichia coli. Protein Expres Purif. 2005; 41(2): 409-416.

Received: March 28, 2014; Accepted: June 04, 2014. 